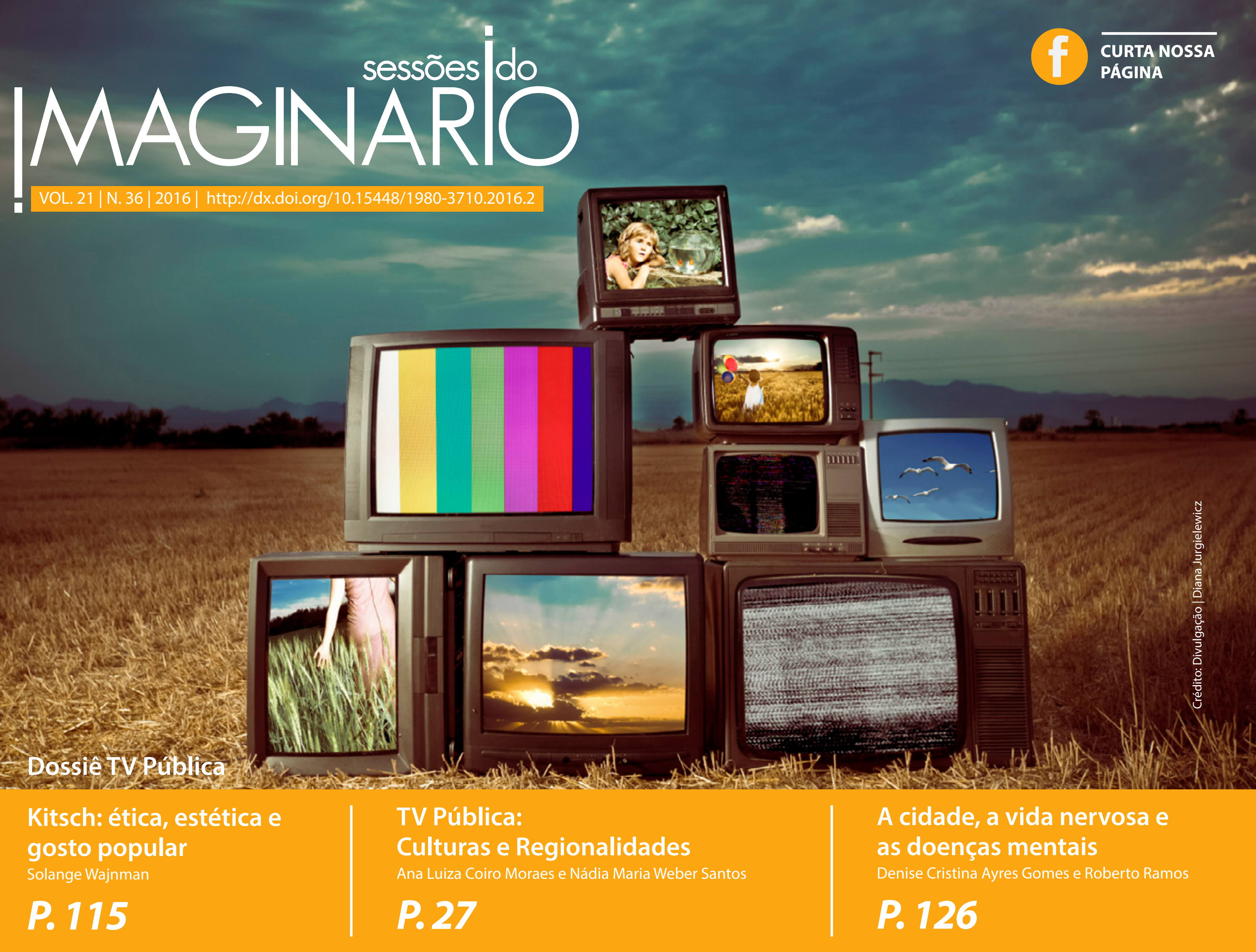




\section{Aperipê TV: a emissora pública e o jornalismo público em questão no estado de Sergipe}

\section{Aperipê TV: the public broadcaster and the public journalism in question in the state of Sergipe}

\section{Lívia Cirne de Azevêdo Pereira² \\ Vitor Curvelo Fontes Belém ${ }^{3}$}

\section{DOSSIÊ}

\section{Resumo}

Este trabalho analisa o emprego dos conceitos de jornalismo público (JP) no telejornal Conexão Aperipê, exibido pela Aperipê TV, emissora estatal do Governo do Estado de Sergipe. Para isso, foi realizada uma análise de conteúdo, com a finalidade de compreender a prática do jornalismo público no âmbito do telejornalismo local, tendo em conta as potencialidades desta prática como ferramenta de fortalecimento da cidadania. A pesquisa apresenta uma breve perspectiva histórica em torno do conceito e o situa no debate conflituoso dos modelos de televisão pública no Brasil. Os resultados mostram que o jornalismo público é uma prática muito distante do telejornalismo da emissora em questão.

\section{Palavras-chave}

Telejornalismo; jornalismo público; TV pública; Conexão Aperipê.

\section{Abstract}

This study analyzes the use of public journalism concepts on the news program Conexão Aperipê, broadcasted by Aperipê TV, public broadcaster of the state of Sergipe. For this, a content analysis was performed to understand the practice of public journalism within the local television news, considering this practice as an empowerment tool of citizenship. The research presents a brief historical perspective of the concept and situates it in the conflicting debate of public television models in Brazil. The results show that public journalism is not a practice in the tele journalism of this broadcaster.

\section{Keywords}

Tele journalism; public journalism; public TV; Conexão Aperipê. 


\section{Introdução}

Existem algumas formas utilizadas para designar o jornalismo público (JP): jornalismo comunitário; jornalismo de serviço público; jornalismo cívico; jornalismo de contato com o público; jornalismo de fonte aberta, entre outros. Os primeiros estudos em torno do conceito envolvem o contexto político norte-americano na década de 80. Com o tempo, a proposta foi se adaptando e agregando novos elementos aos valores-notícia tradicionais. É em torno desse processo que se desenvolve esse estudo, buscando examinar indícios de fraquezas da imprensa no reforço da cidadania. Busca-se, a partir da reflexão sobre o tema, repensar o modelo informativo vigente, a fim de identificar as potencialidades do movimento norte-americano no contexto brasileiro.

Tem-se em conta a capacidade do JP como modelo de jornalismo que favorece a formação do senso crítico dos cidadãos em relação às problemáticas de interesse social. Assim, a pesquisa toma como ponto de partida as potencialidades do jornalismo público como experiência local. $\mathrm{O}$ objeto de análise é o telejornal Conexão Aperipê, exibido de segunda à sexta, das $18 \mathrm{~h} 30 \mathrm{~min}$ às $19 \mathrm{hs}$, na programação da Aperipê TV, emissora estatal, vinculada ao Governo de Sergipe e retransmissora da programação da TV Brasil. A Aperipê tem como lema "Educação, Cultura e Jornalismo Cidadão", com a produção de conteúdo que pretende ser diferenciado em relação às emissoras comerciais. A finalidade é verificar a ocorrência de práticas de jornalismo público, assim como analisar se o telejornal realmente oferece um conteúdo diferenciado.

Este estudo discute a prática do jornalismo público como um caminho possível para a busca da qualidade jornalística. $O$ trabalho não pretende situar o JP como único parâmetro para a prática de um jornalismo de qualidade, mas sim, investigar o que a experiência do movimento norte-americano pode oferecer para o jornalismo brasileiro. Destaca-se que apesar da pesquisa enfocar a prática do jornalismo público em uma emissora estatal, os ideais do JP são conceitos de qualidade jornalística, aplicáveis em organizações públicas ou privadas.

\section{Jornalismo público: cruzamentos}

\section{e adaptações}

A fundação do conceito de jornalismo público ocorre no contexto das eleições presidenciais dos Estados Unidos de 1988. À época, a disputa entre os candidatos George Bush e Michael Dukakis despertou uma insatisfação generalizada da população em relação à cobertura feita pela imprensa do país. A cobertura priorizou a divulgação das pesquisas de intenção de voto, restringindo a pauta jornalística à repercussão gerada em torno disso.

Moraes (2011) identifica que o jornalismo público não surge logo após as eleições, mas ela serviu como marco, pois mostrou aos jornais o quanto a cobertura política estava comprometida com os interesses dos políticos e não dos cidadãos. É por isso que o "novo jornalismo", como coloca Traquina (2001), nasce do anseio pela reforma da prática jornalística em sua relação com o público.

Conforme Rothberg (2011), a cobertura teria se distanciado das propostas apresentadas pelos candidatos e focado os motivos pelos quais eles tinham mais ou menos chances de vencer as eleições. O modelo de cobertura teria alimentado o desinteresse dos leitores de jornais pela política, afastando-os da participação cívica. O baixo comparecimento dos eleitores às urnas é apontado como prova do desinteresse coletivo pela política, tendo em conta a não-obrigatoriedade do voto nos Estados Unidos. Esse descontentamento social provocou a queda nas tiragens dos jornais impressos.

\section{ASSISTA AO VÍDEO}

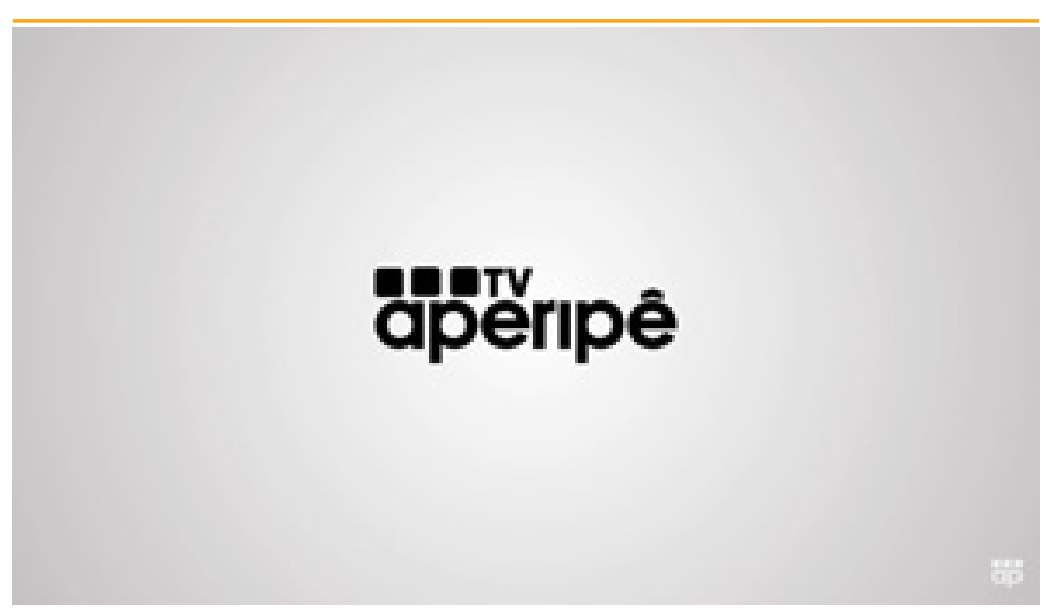

As questões sociais e comunitárias estavam entre as maiores preocupações do JP. No contexto norte-americano, a necessidade de motivar os cidadãos a escolherem candidatos comprometidos com problemas sociais como drogas, violência e pobreza, foi uma das mais importantes bandeiras do movimento, que agrega ao público o papel de agente ativo e transformador no estado democrático. Conforme Moraes (2011), o estreitamento de relações entre jornalistas e cidadãos seria possível através de alterações nos modos de fazer do jornalismo, ou seja, na própria construção da notícia. Os defensores do movimento acreditam que a ação do jornalista deve envolver a participação dos cidadãos em novas formas de cobertura jornalística que favoreçam o engajamento cívico.

Com base em artigo publicado pelo teórico do jornalismo público Leonard Witt em 2004, Barros (2009) mostra como o JP nos Estados Unidos se entrecruza com o "Jornalismo Colaborativo" - que defende a par- 
ticipação do cidadão comum no fornecimento de material informativo às redações - e o "Jornalismo Participativo" (ou Cidadão) - em que qualquer cidadão pode produzir material informativo sem a interferência de um profissional da área.

Entre a contribuição e a participação efetiva da população na produção de notícias, o sucesso da experiência americana de jornalismo público fez com que esse movimento também ganhasse notoriedade internacional, adaptando-se à realidade de cada país. E mesmo diante das diferenças, o modelo norte-americano acabou influenciando fortemente a imprensa brasileira. Práticas já consagradas, como a prestação de serviços, foram absorvidas ao modo de fazer jornalismo público no Brasil. Barros (2009, p. 41) elenca um conjunto de elementos que acredita ser a base das diretrizes do jornalismo público brasileiro:

a) Promover a formação crítica do telespectador para o exercício da cidadania; b) Disponibilizar in

formações que sejam de interesse coletivo; c) Estimular a participação do cidadão nas discussões por meio de instrumentos de interatividade; d) Atentar para a responsabilidade social; e) Evidenciar a capacidade resolutiva da sociedade com exemplos de boas práticas de determinados grupos ou indivíduos (Barros, 2009, p. 41)

Assim, mudam os contextos, mas o cruzamento entre o participativo e o colaborativo se fazem presentes. Um fator fundamental para explicar a prática do JP no Brasil é entender que o provável modelo nacional, também tem forte ligação com a inclusão de questões sociais ou de cidadania na pauta jornalística. É uma es- tratégia, como comenta Silva (2004, p. 13), que mostra uma tendência a investir no social, abrindo espaços nas empresas de mídia para projetos de "cidadania empresarial" (Silva, 2004, p. 13). Na prática, isso representa uma maior diversidade de pautas ou, mais especificamente, a inclusão de temas, como o voluntariado e o combate ao analfabetismo, entre as publicações mais recorrentes.

Numa perspectiva histórica, Garcia (2011) assinala que o JP começa a despontar no cenário midiático brasileiro por volta dos anos 2000, com iniciativas de algumas emissoras públicas de TV nos estados de São Paulo, Rio Grande do Sul, Tocantins, Ceará e Minas Gerais. Os telejornais dessas emissoras passaram a levantar discussões mais aprofundadas nas matérias, aproximando-se dos ideais do jornalismo público. Esse é um contexto em que as emissoras públicas se preocupam mais com a qualidade da programação do que com a audiência, já que não se submetem aos imperativos mercadológicos da TV comercial. É nesse ponto que o debate em torno do conceito, por vezes, se confunde. Mesmo que a nomenclatura da prática jornalística possa parecer associada à esfera governamental, O JP, mesmo nas emissoras estatais, não está vinculado aos interesses dos governantes. O jornalismo público e o caráter de uma emissora pública não são indissociáveis.

\section{TV pública: a mediação entre o Estado e sociedade?}

Para analisar uma emissora do campo público é importante compreender os princípios norteadores dos sistemas televisivos. Isso se deve ao fato de que adoção de sistemas públicos, comerciais ou mistos, interferem nas características dos produtos desses meios. É interessante notar como se constituiu o sistema de radiodifusão britânico, surgido como o ideal de um serviço pú- blico regulado pelo estado, difere do caso brasileiro, em que a radiodifusão tem caráter preponderantemente comercial e dispõe de poucos mecanismos regulatórios.

Na obra A melhor TV do mundo, o modelo britânico de televisão, Laurindo Leal Filho (1997) afirma que o modelo britânico de rádio e televisão tem bases firmadas no compromisso enquanto veículos da produção cultural da nação, que por esse motivo não podem sofrer interferências políticas ou comerciais. Nesse contexto, a noção de "serviço público" está associada à existência de uma necessidade da população. Desse modo, os veículos públicos são financiados total ou parcialmente pelo próprio público.

Segundo Leal Filho (1997), embora as emissoras públicas buscassem se distinguir do modelo de televisão estatal implantado no leste europeu, a autonomia absoluta das emissoras em relação aos governos nunca existiu de fato. Para ele, o que varia é o nível de interferência. Na maioria das vezes, as emissoras são dirigidas por conselhos diretores, modelo implantado pela $B B C$ que se espalhou pelo mundo, inclusive no Brasil com a TV Cultura e a Empresa Brasil de Comunicação (EBC). O modo como os membros do conselho são escolhidos e o tipo de financiamento são fatores determinantes do nível de influência do governo sobre as emissoras.

Como ressalta Rothberg (2011), diferentemente do Brasil, no Reino Unido, o uso do espectro eletromagnético é tido como de grande importância. No Brasil, as emissoras comerciais se portam como produtoras de um serviço gratuito à população, como proprietárias do espectro e não concessionárias, permanecendo livres de qualquer tipo de avaliação em termos de sua responsabilização diante do público. Ressalta-se, no entanto, que pela lei, mesmo as empresas privadas são dependentes de licença pública e dos controles regulatórios.

Conforme Valente (2009), o motivo para o surgimen- 
to da televisão pública no Brasil foi a demanda por educação, já que na década de 1960, o país se encontrava em processo de industrialização e precisava de mão de obra qualificada. Em 1967, o governo militar regulou a modalidade de TV educativa, através do Decreto-Lei n० 236. A radiodifusão do campo público surge com a Rádio MEC (Ministério da Educação e Cultura), em 1936, com produção de conteúdo educativo. Em 1969, o governo do Estado de São Paulo adquiriu a TV Cultura do

grupo de Diários e Emissoras Associados. Nesse mesmo período, teve início a implantação de emissoras educativas pelos governos estaduais.

Um novo passo para a radiodifusão pública do Brasil foi dado em 2007, quando o governo federal criou, através da Lei no 11.652, a Empresa Brasil de Comunicação (EBC), empresa pública responsável por gerir as emissoras do executivo, com uma postura pretensamente pública. Segundo Valente (2009), o surgimen-

\begin{tabular}{|c|c|}
\hline Características agrupadas & Categorias \\
\hline $\begin{array}{l}\text { - Enquadramentos temáticos } \\
\text { - Informações mais contextualizadas } \\
\text { - Discussão e aprofundamento nos temas debatidos } \\
\text { - Promoção de debates sobre problemas enfrentados } \\
\text { pelas cidades }\end{array}$ & Aprofundamento dos temas abordados \\
\hline $\begin{array}{l}\text { - Aproximação com as comunidades } \\
\text { - Mais interação com o público } 9\end{array}$ & Assuntos comunitários e interação com público \\
\hline $\begin{array}{l}\text { - Alimentar o compromisso cívico e participação dos } \\
\text { cidadãos }^{10} \\
\text { - Mobilizar participação social } \\
\text { - Criação e apoio a campanhas sociais e comunitárias }\end{array}$ & $\begin{array}{l}\text { Compromisso em mobilizar a participação social dos } \\
\text { cidadãos }\end{array}$ \\
\hline - Menor uso de fontes oficiais (múltiplas fontes) $)^{13}$ & Tipificação das fontes \\
\hline $\begin{array}{l}\text { - Prestação de serviços }{ }^{14} \\
\text { - Orientação do público (endereços, telefones úteis, } \\
\text { sites, etc.) }^{15} \\
\text { - Oferta de soluções alternativas }{ }^{16}\end{array}$ & Elementos de serviço e orientação do público \\
\hline $\begin{array}{l}\text { - Divulgação de exemplos de boas práticas de } \\
\text { determinados grupos ou indivíduos }{ }^{17}\end{array}$ & $\begin{array}{l}\text { Divulgação de exemplos de boas práticas de grupos } \\
\text { ou indivíduos }\end{array}$ \\
\hline $\begin{array}{l}\text { Questões sociais ou de cidadania na pauta jornalística }{ }^{18} \\
\text { Busca de soluções para problemas sociaisi }\end{array}$ & Abordagem de questões sociais e de cidadania \\
\hline
\end{tabular}

Tabela 1: Características de jornalismo público agrupadas em categorias to da TV Brasil representou a tentativa de superar o passado das televisões estatais, associadas ao poder de governantes e autoridades. A EBC gere a TV Brasil, TV Brasil Internacional, Agência Brasil, Radioagência Nacional e o sistema público de rádio. A TV Brasil é considerada a primeira televisão efetivamente pública com abrangência nacional, com programação voltada ao jornalismo e programas culturais.

Uma questão conflituosa em relação ao modelo de gestão da EBC está relacionada ao fato de que em todas as quatro instâncias, o presidente da República é responsável pela escolha dos conselheiros. Segundo Bucci (2010), se comparada com a Radiobrás e a TVE do Rio de Janeiro, emissoras que deram origem à TV Brasil, ela é bem mais avançada como entidade de comunicação pública, mesmo assim ainda está sujeita ao poder estatal, que pode constrangê-la, pressioná-la e enquadrá-la com instrumento de propaganda. Sobre essa questão, Bucci (2010) comenta: "A gestão é o ponto crítico da fase atual da nossa televisão pública, a qual envolve, mais precisamente, os três requisitos para a sua independência - natureza jurídica, padrão de financiamento e modo de gestão" (Bucci, 2010, p. 17).

A iniciativas ao longo da história problematizam a classificação dos sistemas televisivos no Brasil. De acordo com Nazareno (2007), a Constituição Federal diferencia duas designações: "radiodifusão" e "radiodifusão para fins exclusivamente educativos". Dessa distinção prevista na lei, pode-se inferir que todas as emissoras de televisão abertas podem ser educativas ou não-educativas. A segunda diferenciação é entre emissoras estatais - vinculadas a alguma esfera da Administração Pública - e comerciais - exploradas pela iniciativa privada, sem interferência estatal, exceto para a outorga do canal. O fato é que as conceituações em torno dos 
sistemas confrontam o artigo 223 da Constituição Federal, que estabelece o princípio da complementaridade entre os sistemas privado, público e estatal de radiodifusão. Ou seja, pela lei há três classificações, mas o texto não deixa claro as especificidades de cada uma e expõe a fragilidade em discernir o público do estatal. Mesmo que ambos os modelos sejam de interesse público, a princípio, a emissora pública se caracteriza pelos interesses da sociedade e pauta-se, principalmente, pela educação e cultura; enquanto a estatal, como é o caso

da Aperipê TV, está atrelada ao caráter institucional e à divulgação das ações do Estado. Bucci $(2008$, p. 259260) analisa a definição e aponta que "o estatal deve ser entendido como uma subcategoria do público, ou seja: embora nem tudo que é público seja estatal, tudo que é estatal só pode ser público.". O entendimento é compartilhado por Nazareno (2007) e com a lacuna legal, o debate é constante e conflituoso. As definições podem assumir diferentes características, a depender do contexto, por conta da dependência do financia-

\begin{tabular}{|l|l|}
\hline \multicolumn{1}{|c|}{ Categorias } & \multicolumn{1}{|c|}{ Definiçães } \\
\hline Aprofundamento dos temas abordados & $\begin{array}{l}\text { Avalia se a matéria oferece elementos complementares } \\
\text { que possam auxiliar na compreensão dos fatos ou } \\
\text { assuntos apresentados. }\end{array}$ \\
\hline Assuntos comunitários e interação com o público & $\begin{array}{l}\text { Analisa se o assunto tratado na matéria se relaciona } \\
\text { com as problemáticas das comunidades, tendo o meio } \\
\text { de comunicação como aliado na solução das questões. }\end{array}$ \\
\hline $\begin{array}{l}\text { Compromisso em mobilizar participação social dos } \\
\text { cidadãos }\end{array}$ & $\begin{array}{l}\text { Verifica se o conteúdo noticioso teve preocupação } \\
\text { em incluir os cidadãos como agentes responsáveis e } \\
\text { comprometidos com o meio social. }\end{array}$ \\
\hline Tipificação de fontes & $\begin{array}{l}\text { Analisa a distribuição das fontes com vistas a avaliar } \\
\text { influência exercida pelas fontes oficiais no noticiário. }\end{array}$ \\
\hline Elementos de serviço e orientação do público & $\begin{array}{l}\text { Verifica se a matéria auxilia o público por meio da oferta } \\
\text { de elementos de serviços (telefones úteis, endereços, } \\
\text { etc.) e orientação }\end{array}$ \\
\hline $\begin{array}{l}\text { Divulgação de exemplos de boas práticas de grupos } \\
\text { ou indivíduos }\end{array}$ & $\begin{array}{l}\text { Na perspectiva do jornalismo público, a difusão dos } \\
\text { bons exemplos, estimula a capacidade resolutiva da } \\
\text { sociedade. }\end{array}$ \\
\hline Abordagem de questões sociais e de cidadania & $\begin{array}{l}\text { Analisa a participação dos meios de comunicação } \\
\text { no tocante à discussão de assuntos sociais e no } \\
\text { fortalecimento da cidadania. }\end{array}$ \\
\hline
\end{tabular}

Tabela 2: Definições das categorias de análise mento do poder público. Assim, se faz necessário o esclarecimento de que este estudo considera ambos os modelos como públicas, que se diferenciam pelas instâncias da administração.

\section{Aperipê TV em busca de uma}

\section{aproximação com o jornalismo público}

O mercado de TV aberta no Estado de Sergipe é formado por um reduzido número de emissoras locais afiliadas a grandes redes nacionais: TV Sergipe (Rede Globo), TV Atalaia (Record), TV Canção Nova, além das emissoras que têm o sinal retransmitido localmente, mas que não são afiliadas. A Aperipê TV é a única emissora estatal, atrelada ao governo do estado e, portanto, também é pública. Por isso mesmo, a história da emissora expõe um jogo de interesses entre grupos políticos locais. Santos (2011) resume o contexto de surgimento do canal:

A TV Aperipê foi criada por um governo que temia o poder e a influência da afiliada da Rede Globo no estado, sempre rigorosa e crítica em relação a governos adversários dos interesses políticos dos proprietários (a tradicional família Franco), ao mesmo tempo condescendente diante de governos aliados. [...] Assim, a Aperipê esteve útil e viva enquanto o governo necessitava de um instrumento de voz. Logo que as divergências entre as elites locais foram sanadas resultando em sucessivos acordos político-partidários, acabou esquecida e entregue ao abandono, não chegando a fechar as portas graças aos poucos funcionários que se mantiveram fiéis ao ideal de uma TV pública num estado de meios de comunicação concentrados, até então, nas mãos de um pequeno núcleo de famílias tradicionais (San- 
tos, 2011, p. 163)

A emissora está vinculada à Fundação Aperipê, que surgiu através da Lei no 1.759, de 11 de dezembro de 1972, e que, por sua vez, está vinculada à Administração Pública do Estado de Sergipe, com a finalidade de prestar os serviços de radiodifusão. Inicialmente a Fundação era responsável apenas pela rádio Aperipê AM 630, sendo a emissora de TV criada apenas em janeiro de 1985. Já no ano de 1995, entra no ar a rádio Aperipê FM 109.9, completando os três veículos administrados pela Fundação Aperipê.

A estrutura administrativa da Fundação Aperipê é formada por um Conselho Deliberativo, com participação popular, e por uma Diretoria Executiva dividida em outras diretorias específicas. Um estudo desenvolvido pelo pesquisador da Universidade de Brasília, Sivaldo Pereira da Silva, avaliou 34 organizações de mídia do campo público, dentre elas a Fundação Aperipê. A análise considerou critérios relacionados às estruturas organizativas, tais como: transparência; participação; autonomia administrativa; independência financeira. Um importante dado apontado pelo estudo sobre a Fundação Aperipê, diz respeito à composição do Conselho Deliberativo, constituído por sete membros, dos quais $86 \%$ estão subordinados ao titular do Poder Executivo, o governador do estado. Sendo assim, a participação popular nas decisões da fundação é quase inexistente (Silva S., 2013).

Atualmente a Fundação Aperipê integra a ARPUB Associação das Rádios Públicas do Brasil - e a Associação Brasileira das Emissoras Públicas, Educativas e Culturais - ABEPEC. Desde 02 de dezembro de 2008, a Aperipê TV é associada à Empresa Brasil de Comunicação (EBC), retransmitindo os conteúdos da TV Brasil, além de contribuir com alguns conteúdos locais exibidos em rede nacional, a exemplo do Estação Periferia. A Aperipê TV que já realizava suas transmissões em sinal aberto no canal 2 VHF, em 2014 passou a operar também com sinal digital, compreendendo os municípios da Grande Aracaju, além de estar presente em operadoras de TV por assinatura, atuantes no estado.

A Aperipê TV apresenta-se como uma emissora pública e adota o mote "Educação, Cultura e Jornalismo Cidadão", conforme informações disponibilizadas em seu site:

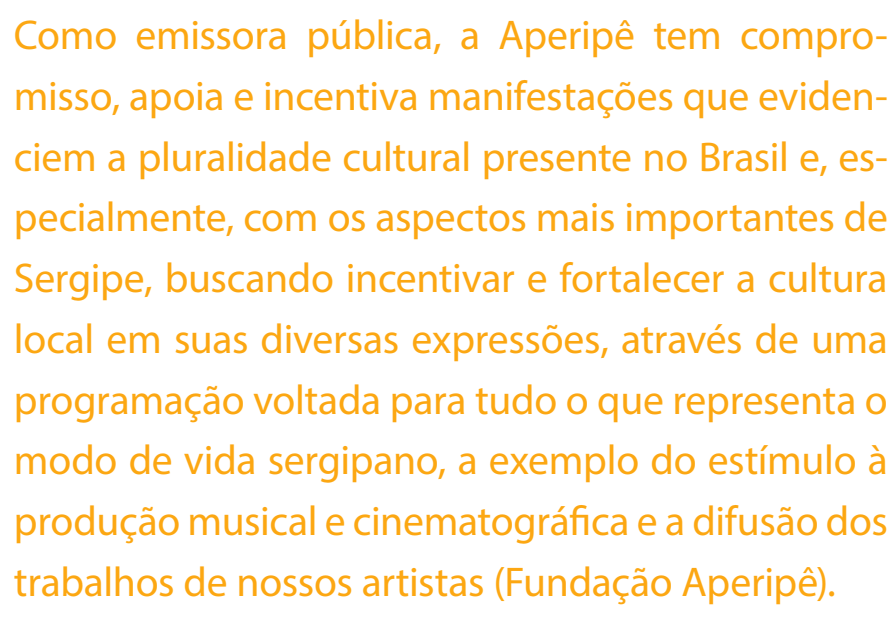
misso, apoia e incentiva manifestações que evidenciem a pluralidade cultural presente no Brasil e, especialmente, com os aspectos mais importantes de Sergipe, buscando incentivar e fortalecer a cultura local em suas diversas expressões, através de uma programação voltada para tudo o que representa o modo de vida sergipano, a exemplo do estímulo à produção musical e cinematográfica e a difusão dos trabalhos de nossos artistas (Fundação Aperipê).

No ano de 2015, a Aperipê TV passou por alterações no seu corpo administrativo, o que refletiu em mudanças na grade de programação, com a expansão do espaço reservado aos conteúdos locais. Atualmente, a emissora mantém uma linha de programas voltados às produções culturais, sendo eles: Olha aí (audiovisual), Plural (literatura), Nossa Terra Nossa Gente (show), Clip Mais (música), Arte Solidária (música), Expressão (artes) e Entre Amigos (entrevistas). Com uma ligação mais próxima ao gênero documentário, a Aperipê TV apresenta ainda o Estação Periferia (arte e cultura). São exibidos diariamente os jornalísticos Sergipe em Debate, Segurança em Alerta (policial), Utilidade Pública e Conexão Aperipê. A grade jornalística da emissora ainda conta com os programas de entrevista Crimes Contra a Saúde, Dina Bispo, Super Vip, 10 necessários e Superação. No gênero reportagem têm

\begin{tabular}{|c|c|c|}
\hline \multicolumn{2}{|c|}{ Dados e categorias analisadas } & \multirow{2}{*}{$\begin{array}{l}\text { Percentual (\%) } \\
72,97\end{array}$} \\
\hline & Reportagem & \\
\hline $\begin{array}{l}\text { Gêneros } \\
\text { iornalísticos }\end{array}$ & Entrevista & 16,21 \\
\hline & Nota & 10,81 \\
\hline \multirow{12}{*}{$\begin{array}{l}\text { Divisão de } \\
\text { editorias }\end{array}$} & Cidades & 24,32 \\
\hline & Cultura & 16,21 \\
\hline & Economia & 13,51 \\
\hline & Política & 10,81 \\
\hline & Esporte & 8,10 \\
\hline & Saúde & 8,10 \\
\hline & Segurança & 5,40 \\
\hline & Cidadania & 2,70 \\
\hline & Utilidade pública & 2,70 \\
\hline & Ciência & 2,70 \\
\hline & Meio ambiente & 2,70 \\
\hline & Moda & 2,70 \\
\hline \multirow{2}{*}{$\begin{array}{l}\text { Tipificação de } \\
\text { fontes }\end{array}$} & Oficiais & 22,35 \\
\hline & Não-oficiais & 77,65 \\
\hline $\begin{array}{l}\text { Elementos } \\
\text { de serviço e } \\
\text { orientação do } \\
\text { público }\end{array}$ & Presente & 16,21 \\
\hline $\begin{array}{l}\text { Aprofundamen- } \\
\text { to dos temas } \\
\text { abordados }\end{array}$ & Presente & 30,55 \\
\hline $\begin{array}{l}\text { Divulgação de } \\
\text { boas práticas de } \\
\text { indivíduos ou } \\
\text { grupos }\end{array}$ & Presente & 10,81 \\
\hline $\begin{array}{l}\text { Assuntos } \\
\text { comunitários e } \\
\text { interação com o } \\
\text { público }\end{array}$ & Presente & 16,21 \\
\hline $\begin{array}{l}\text { Mobilização } \\
\text { social / temas } \\
\text { sociais e de } \\
\text { cidadania }\end{array}$ & Presente & 8,10 \\
\hline
\end{tabular}

Tabela 3: Dados quantitativos do Conexão Aperipê 
destaque Sergipe Rural e Inclusão e Saúde.

Além disso, a grade da Aperipê TV inclui programas institucionais como Sergipe Justiça, TCE na TV (do Tribunal de Contas do Estado de Sergipe), Hora do Empreendedor (SEBRAE - Serviço de Apoio às Micro e Pequenas Empresas) e Seu Imóvel (Conselho Regional dos Corretores de Imóveis - CRECI/SE), realizados em parceria com as respectivas entidades. A reformulação da grade também incluiu alguns programas de produção independente que já foram exibidos pela TV Atalaia (afiliada Record): Paulo Lavinge; Tudo Sobre Rodas; Noivos e Formandos. Também são apresentados programas religiosos Pense e Repense, Santa Missa, Conceitos de Vida e Salto Quântico.

Para fins deste estudo, o objeto empírico restringese ao telejornal Conexão Aperipê.

Conexão Aperipê: constatações empíricas

A presente análise tem o objetivo de verificar a ocorrência de práticas de jornalismo público no telejornal Conexão Aperipê. A pesquisa foi realizada em dezembro de 2014, compreendendo cinco edições do telejornal em dias alternados. $O$ método de pesquisa escolhido é a análise de conteúdo. Herscovitz (2008) identifica a análise de conteúdo como um método capaz de avaliar grande volume de informações, reduzidas a categorias e baseadas em regras explícitas e previamente definidas, com o objetivo de fazer inferências lógicas. É exatamente isso que se propõe com o quadro teórico apresentado na Tabela 1, construído com base nos referenciais teóricos revisados no percurso deste trabalho. Esses elementos foram agrupados, dando origem às categorias de análise.

A partir dos critérios desta análise, as categorias expostas na Tabela 1 são definidas conforme a Tabela 2.
Da verificação quantitativa das características gerais do telejornal e das categorias de jornalismo público elencadas e definidas acima, temos a Tabela 3.

O telejornal Conexão Aperipê, exibido de segunda à sexta-feira, é invariavelmente dividido em três blocos. A duração média de cada edição, no período analisado, foi de 23 minutos. Ao todo foram analisadas 37 matérias, entre reportagens $(72,97 \%)$, entrevistas em estúdio $(16,21 \%)$ e notas $(10,81 \%)$. Mesmo com um tempo relativamente curto, o telejornal abordou temáticas diversas. $\mathrm{Na}$ distribuição percentual das editorias correspondentes aos assuntos noticiados temos: Cidades $(24,32 \%)$; Cultura (16,21\%); Economia (13,51\%); Política (10,81\%); Esportes (8,1\%); Saúde (8,1\%); Segurança (5,4\%); Cidadania, Utilidade Pública, Ciência, Meio Ambiente e Moda responderam por $2,7 \%$, cada uma.

A primeira categoria analisada foi a tipificação de fontes, divididas entre fontes oficias e não-oficiais. Uma das mais importantes críticas do jornalismo público diz respeito ao uso excessivo das fontes oficiais incorporado ao cotidiano das redações. No telejornal foram registradas as participações de 94 pessoas ouvidas como fontes, das quais $22,35 \%$ foram oficiais e $77,65 \%$ não-oficiais. Interessante notar que o maior número de fontes não-oficiais consultadas pelo telejornal não significou maior representatividade da população, tendo em conta o papel ilustrativo dado ao discurso popular. A necessidade de ouvir os cidadãos e procurar responder às questões por eles identificadas requer uma postura de colaboração dos veículos de informação em relação à comunidade. Quando as pautas jornalísticas priorizam a importância das informações prestadas pelas fontes oficiais e reservam lugar secundário às fontes populares, o princípio do interesse público passa a assumir o segundo plano, comprometen- do a efetividade do papel social da informação.

Se retomarmos o aspecto da utilidade pública da informação chegamos a outro ponto importante do JP praticado no Brasil: o jornalismo de serviço. É relevante destacar que a prestação de serviços por meio da oferta de informações para orientação do público é uma prática relativamente comum na imprensa brasileira. Ao lidar com assuntos que impactam diretamente no cotidiano social (como problemas na saúde, educação, segurança, etc.), os jornalistas lidam com demandas às quais os atores sociais buscam encontrar soluções cabíveis por meio da divulgação dos fatos. O que os ideais do JP ressaltam é que a oferta dos conteúdos informativos deve dotar os cidadãos do máximo de informações necessárias à superação do problema de ordem coletiva.

Desse modo, o segundo critério de análise da tabela 3 avaliou a inclusão de elementos de serviço e orientação do público nas matérias veiculadas. Ao todo, foram registradas seis matérias $(16,21 \%)$ que trouxeram algum conteúdo voltado à orientação ou esclarecimento do público sobre determinado tema. O percentual é pouco expressivo considerando-se inclusive a abrangência local do telejornal e o número questões de alcance social apresentadas no telejornal. Nesse sentido, o espaço destinado aos assuntos comunitários também foi pouco representativo, aparecendo em $16,21 \%$ das matérias analisadas. As outras duas categorias associadas a esta última, são: o compromisso em mobilizar a participação social dos cidadãos e a abordagem de temas sociais e de cidadania. Ambas apareceram $8,1 \%$ de todas as matérias

Ao se analisar um telejornal de emissora do campo público, tem-se em conta que o papel desses veículos é oferecer conteúdo diferenciado em relação aos canais privados e às demandas comerciais, fazendo valer a complementaridade dos sistemas de televisão público 
e privado. Um aspecto importante constatado na análise do Conexão Aperipê é a existência de um menor número de notas e maior espaço dedicado às reportagens e entrevistas; mesmo assim, com o telejornal dispondo de tempo para análise e discussões, na maior parte das vezes, não conseguiu satisfazer o aprofundamento necessário aos temas apresentados, segundo os critérios que foram categorizados na Tabela 2.

$\mathrm{Na}$ categoria da análise que avaliou o aprofundamento do conteúdo do telejornal, buscou-se perceber o quanto cada uma das matérias apresentou aspectos contextuais relacionados aos temas, facilitando e ampliando a compreensão por parte do público (Garcia, 2011). Em onze situações (30,55\%), foi notada a apresentação de informações contextualizadas. O espaço dedicado a entrevistas contribuiu significativamente com esse número, tendo em conta a possibilidade de discussão e aprofundamento dos assuntos. Quando se compara o tempo dedicado a cada matéria e a baixa satisfação do critério de aprofundamento dos temos, fica claro que a maior parte do telejornal manteve um baixo nível de elaboração das abordagens.

Além de propor coberturas jornalísticas que privilegiem a participação social dos cidadãos, o jornalismo público também sugere que a escolha dos assuntos a serem noticiados são instrumentos capazes de mobilizar os indivíduos na vida pública. É por isso que o JP convoca os jornalistas a atuarem na divulgação de boas práticas de indivíduos e grupos, como forma de mostrar a capacidade da sociedade em resolver as problemáticas que lhes são postas (Barros, 2009). Em 10,81\% do conteúdo exibido, foi notada a presença desse elemento. Interessante notar que a classificação dada pelos valores-notícia tradicionais atribui menor importância às boas notícias.

\section{Considerações finais}

A presente pesquisa teve a finalidade de averiguar a prática do jornalismo público no telejorna local Conexão Aperipê. É importante frisar que não buscamos enquadrar o JP como único critério de qualidade jornalística, mas sim, como uma possibilidade para o jornalismo brasileiro dentro de um conjunto mais amplo. Apesar desta pesquisa analisar um telejornal de emissora do campo público, o JP é um caminho possível para a prática jornalística de empresas públicas ou privadas.

Os dados referentes às cinco edições demonstraram que o telejornal Conexão Aperipê não incorpora, de forma substantiva, a prática do jornalismo público. A análise ainda mostrou que o telejornal não consegue nem mesmo oferecer uma proposta jornalística diferenciada das emissoras comerciais, não de modo a oferecer conteúdo jornalístico de mais qualidade.

Alguns vícios profissionais comuns aos jornais das emissoras comerciais são visíveis no conteúdo do Conexão Aperipê, como a construção de narrativas simplificadas, a partir de dois posicionamentos opostos. Nestes casos, a máxima de apresentar os dois lados da questão, seguida à risca, desconsidera o debate plural de ideias e posicionamentos dos cidadãos. Na maior parte das vezes, o espaço reservado às fontes populares se incumbe do papel de ilustrar as informações e pouco contribui para a representação do pluralismo de visões necessário ao debate social. Desse quadro, é possível extrair que o estímulo à mobilização e participação social dos cidadãos são assuntos quase inexistentes no telejornal. A presença de elementos de serviço e orientação do público, comuns na maioria dos telejornais, também tem baixa representatividade no telejornal analisado.

A existência de um número reduzido de matérias e o maior tempo dedicado aos temas, não significou a oferta de conteúdo de mais qualidade ao público, já que a maioria das matérias apresentou abordagens superficiais. Nesse sentido, as entrevistas em estúdio foram um diferencial, talvez o único do Conexão Aperi$p \hat{e}$, já que, na maioria das vezes, conseguiram oferecer uma visão analítica de temas de interesse social.

A escolha de um telejornal da Aperipê TV coloca em questão outros fatores ligados à independência editorial da emissora. Isso porque, embora se defina como TV pública, a Aperipê é uma emissora estatal vinculada ao Governo de Sergipe, ou seja, financeiramente dependente das verbas do Estado. Esse fator faz com que a emissora esteja sujeita às ingerências dos governantes. Nem mesmo a estrutura baseada em conselho administrativo concede autonomia para a emissora, já que a maior parte dos conselheiros são pessoas subordinadas ao representante maior do poder executivo estadual. Se por um lado, os interesses mercadológicos das emissoras comerciais podem ser vistos como limitação para a prática isenta do jornalismo, a mesma lógica pode ser empregada para as emissoras estatais em relação aos governantes.

O caso da Aperipê TV se repete em diversas emissoras vinculadas a alguma das esferas da administração pública. A conquista da independência financeira é fator determinante e a principal limitação atual para a constituição de um sistema público de televisão no país. A criação da Empresa Brasil de Comunicação (EBC), que administra a TV Brasil, foi um marco importante para a televisão pública brasileira. Mesmo no caso da EBC, a independência financeira e administrativa é uma questão a ser superada.

Como apontado no decorrer da análise, a linha editorial do jornalismo praticado pela Aperipê TV permanece atrelada a um viés institucional que caracteriza as 
emissoras estatais no Brasil. Nesse sentido, ao adotar a denominação de uma emissora pública voltada à "Educação, Cultura e Jornalismo Cidadão", a Aperipê busca se desprender do estereótipo de uma emissora porta-voz dos posicionamentos e interesses governamentais. Pela análise, pudemos perceber que o conteúdo jornalístico da emissora se mostrou preocupado em gerar uma imagem positiva de órgãos e setores da administração pública. Nas situações em que os assuntos abordados trataram de problemas relativos à ineficiência dos serviços públicos, os posicionamentos dos setores públicos não foram sequer mencionados. Enquanto isso, as ações e projetos desenvolvidos no âmbito dos órgãos públicos receberam destaque no telejornal.

Afora os constrangimentos internos e externos aos meios de comunicação, o telejornalismo local demonstra grande potencial para a implementação dos conceitos do jornalismo público. Como uma prática voltada à informação e, acima disso, a formação de cidadãos comprometidos com as questões de interesse comum, o jornalismo público precisa ser encarado como missão social, uma forma de contribuir para o fortalecimento da democracia.

\section{Referências}

BARROS, Luís Gustavo Martins. O Jornalismo Público praticado pelo programa Cidades e Soluções. 2009. 115 f. Monografia (Especialização). Instituto de Educação Superior de Brasília-IESB, Brasília, 2009.

$\mathrm{BUCCl}, \mathrm{E} .$. É possível fazer televisão pública no Brasil?. Novos Estudos CEBRAP (Impresso), v. 88, pp. 5-18, 2010. https:/doi.org/10.1590/S0101-33002010000300001

BUCCl, Eugênio. Em Brasília 19 horas. A guerra entre a chapa-branca e o direito à informação no primeiro governo Lula. Rio de Janeiro: Record, 2008.

CASTILHO, Carlos. Jornalismo Público. 1997. Instituto Gutenberg. Boletim no 15, maio-junho 1997. Disponível em: <http://www.igutenberg.org/casti15. html>. Acesso: 13 nov. 2014.

FERREIRA, Vânia. Impressões sobre Jornalismo Público. In: PRADO, Mônica (Org). Coletânea Pública: Práticas de comunicação Pública em Brasília. Brasília: Entreposto Acadêmico e DCE - UniCEUB, 2008, pp. 17-24.

GARCIA, M. Tereza. Proposta de Jornalismo Público da TV Cultura: o que há de novo nas pautas e produção do telejornal?. 216 f. Tese (Doutorado). Pontifícia Universidade Católica de São Paulo, São Paulo, 2011.

HERSCOVITZ, Heloiza Golbspan. Análise de conteúdo em jornalismo. In LAGO, Claúdia; BENETTI, Marcia. (orgs.) Metodologia de Pesquisa em Jornalismo. Petropólis, RJ: Vozes, 2008.

LEAL FILHO, L.. A melhor TV do mundo. O modelo britânico de televisão. 1. ed. São Paulo: Summus Editora, 1997.

MORAES, B.S. Jornalismo Público: um olhar sobre o Repórter Brasil. 2011. 145 f. Dissertação (Mestrado) Universidade de Brasília. Faculdade de Comunicação Universidade de Brasília, Brasília, 2011.

NAZARENO, Claudio. A implantação da TV pública no Brasil. Consultoria Legislativa da Câmara dos Deputados. Brasília (DF), 2007.

PESSONI, Arquimedes. Jornalismo público americano: leitor como cidadão. Revista IMES. Comunicação, São Caetano do Sul, v. 10, jan-jun, p. 58-68, 2005.

ROTHBERG, Danilo. Jornalismo Público: informação, cidadania e televisão. São Paulo: Editora Unesp, 2011.

SANTOS, Luciano Correia dos. TV Caju e TV Cidade: o conteúdo local no mercado de TV por assinatura em Aracaju. São Cristóvão: Editora UFS, 2011.

SILVA, Luiz Martins da. Jornalismo Público: o social como valor-notícia. In: Luiz Martins (Org.) Jornalismo Público. Brasília-DF: Casa das Musas. Coleção Textos em Comunicação. Ano II, vol. II, n 5, 2004.

SILVA S., Sivaldo. Dimensões estruturais da mídia pública no Brasil: Análise comparativa de indicadores-chaves em organizações de radiodifusão. Ciberlegenda (UFF. Online), v. 1, 2013. pp. 47-60.

TRAQUINA, Nelson. 0 estudo do jornalismo no século XX. São Leopoldo: Unisinos, 2001.

VALENTE, Jonas. Sistema público de comunicação do Brasil. In: Sistemas públicos de comunicação no mundo: experiências de doze países e o caso brasileiro. São Paulo: Paulus, Intervozes, 2009.

Referências Audiovisuais

CONEXÃO APERIPÊ. Aracaju: Aperipê TV, 2 de dezembro de 2014. Programa de TV.

CONEXÃO APERIPÊ. Aracaju: Aperipê TV, 10 de dezembro de 2014. Programa de TV. 
CONEXÃO APERIPÊ. Aracaju: Aperipê TV, 18 de 8 Castilho (1997)

dezembro de 2014. Programa de TV.

9 Rothberg (2011)

CONEXÃO APERIPÊ. Aracaju: Aperipê TV, 26 de dezembro de 2014. Programa de TV.

10 Haas e Steiner (apud Rothberg, 2011)

CONEXÃO APERIPÊ. Aracaju: Aperipê TV, 29 de 11 Moraes (2011) dezembro de 2014. Programa de TV.

\section{Notas}

1 O texto foi feito com a colaboração de Fernando Moreira de Souza, graduando em Ciências Sociais pela Universidade Federal do Sergipe. E-mail: fms.3008@ gmail.com.

2 Doutora em Comunicação pela Universidade Federal do Pernambuco. Professora da Universidade Federal do Maranhão (CCSST - R. Urbano Santos, s/n, Centro. Cep: 65900410. Imperatriz/MA). E-mail:liviacirne@ gmail.com.

3 Doutorando em Comunicação e Semiótica pela Pontifícia Universidade Católica de São Paulo. Professor da Universidade Federal do Maranhão (CCSST - R. Urbano Santos, s/n, Centro. Cep: 65900410. Imperatriz/MA). E-mail: vitorcfb@gmail.com.

\section{Garcia (2011)}

13 Rothberg (2011)

14 Barros (2009)

15 Silva (2004)

16 Rothberg (2011)

17 Barros (2009)

18 Silva (2004)

19 Schaffer (apud Pessoni, 2005)

4 Rothberg (2011)

5 Rothberg (2011)

6 Garcia (2011)

7 Garcia (2011) 